\title{
Changes of physicochemical properties of Cheonggukjang prepared with various soybean cultivars and Bacillus subtilis HJ18-9
}

\author{
Na-Young Gil, Jin Song, Jeong Seon Eom, Shin-Young Park, Hye-Sun Choi* \\ Fermented Food Science Division, Department of Agrofood Resources, NAAS, RDA, Wanju 55365, Korea
}

\section{장류용 주요 콩품종 및 Bacillus subtilis HJ18-9 균주에 따른 청국장의 품질특성 변화}

\author{
길나영 · 송진 · 엄정선 · 박신영 · 최혜선* \\ 농촌진흥청 국립농업과학원 농식품자원부 발효식품과
}

\begin{abstract}
The purpose of this study was to investigate changes in the amino acid content and physicochemical properties of Cheonggukjang prepared by using various soybean cultivars (Daewon, Deapung, Seadanbeak, and Taekwang) and a functional microorganism (Bacillus subtilis HJ18-9). These soybeans were conventional Cheonggukjang (control) and Cheonggukjang fermented with Bacillus subtilis HJ18-9 (treated). The moisture contents of steamed, control, and treated soybean were $62.45 \sim 67.12 \%, 63.28 \sim 67.14 \%$, and $64.50 \sim 66.87 \%$; amino-type nitrogen contents were $6.53 \sim 24.25 \mathrm{mg} \%$, 27.63 122.09 mg\%, and 37.29 133.48 mg\%; and ammonia-type nitrogen contents were $26.92 \sim 47.95$ $\mathrm{mg} \%$, $45.45 \sim 156.36 \mathrm{mg} \%$, and $28.02 \sim 121.13 \mathrm{mg} \%$, respectively. The umami taste associated with several amino acids (aspartic acid and glutamic acid) in Cheonggukjang was lower than that for steamed soybeans, while the bitter taste from amino acids (methionine, valine, isoleucine, leucine, and phenylalanine) was higher than that for steamed soybeans. The result of sodium dodecyl sulfate-polyacrylamide gel electrophoresis analysis showed that the molecular weight of steamed soybeans was less than $100 \mathrm{kDa}$, while control and treated groups showed low molecular weights below $34 \mathrm{kDa}$, confirming their protein hydrolysis to small molecular weight. These results are information for developing functional fermented soybean paste and diversification using soybean cultivars.
\end{abstract}

Key words : soybean cultivars, Cheonggukjang, amino acid, fermentation

\section{서 론}

대두는 단백질을 $40 \%$ 정도 함유하고 있어, 오랜 세월동 안 쌀 위주의 식생활을 해온 한국인의 식생활에 양질의 단백질 급원으로 이용되어져 왔다(1). 탄수화물과 지방함 량은 각각 $30,20 \%$ 정도로 아미노산 및 지방산의 조성이 우수한 것으로 알려져 있으며, 기능성 물질로 isoflavones, phytic acid, saponins, trypsin inhibitor 등이 있다(2). 이러한

*Corresponding author. E-mail : choihs9587@korea.kr Phone : 82-63-238-3624, Fax : 82-63-238-3843

Received 26 September 2016; Revised 11 November 2016; Accepted 16 November 2016.

Copyright (c) The Korean Society of Food Preservation. All rights reserved.
대두는 소화흡수율과 영양을 높기기 위해 두부나 장류처럼 가공하거나 발효하여 섭취해 왔으며(3), 콩의 품종에 따른 청국장에 관한 연구는 발효방법 및 대두품종을 달리한 청국 장의 향기성분(4), 검은 콩 품종에 따른 청국장의 항산화능 및 혈전용해능(5), 콩 품종별 청국장의 가공적성 구명(6) 등 다양한 연구가 진행되어져 왔다.

청국장은 콩을 원료로 한 발효식품으로 Bacillus 속 등의 미생물 유래 효소작용으로 고분자의 단백질이 펩타이드 그리고 아미노산으로 분해되어 특유의 풍미를 갖게 되며, 소금을 첨가하지 않은 상태로 단기간 발효하기 때문에 소금 의 과잉섭취를 줄일 수 있은 식품이다(7). 청국장의 기능성 연구는 고혈압 방지, 지질대사 개선, 혈전 용해능, 항돌연변 이, 항암성, 항산화성 등의 효과가 있는 것으로 보고되고 있다 $(8,9)$. 청국장 이용 상품화 기반연구는 청국장 첨가 카 
스텔라(10), 청국장 분말 첨가 두부(11), 율무 청국장 분말 첨가 쿠키(12) 등이 있으며, 당귀·지황·홍삼을 첨가한 청국 장(13), 홍삼을 이용한 청국장(14)과 같이 청국장에 기능성 소재를 첨가 하여 효능을 강조한 연구가 진행되고 있다. 또한 청국장 점질물에 관한 연구(15), 숙성중의 향기성분에 관한 연구(16), 균주를 달리한 청국장 제조 $(17,18)$ 에 관한 연구 등 많은 연구가 진행되고 있다. 청국장의 일반적인 품질특성 연구는 많이 진행된 반면 품종별 청국장 가공적성 이나 맛에 관여하는 요소에 대한 연구가 부족한 실정이다. 대풍, 태광, 대원콩은 장류용으로 이용되고 있으며, 새단백 은 두부와 같은 가공용으로 사용되고 있다. 본 연구는 장류 및 가공용 주요 콩품종 및 유용발효미생물인 Bacillus subtilis HJ18-9를 starter로 사용한 청국장의 이화학적인 특 징과 맛에 관여하는 아미노산 및 유기산 구성을 비교하여 청국장의 품질을 향상시키는데 필요한 기초자료를 제시하 고자 하였다.

\section{재료 및 방법}

\section{실험재료 및 청국장제조}

본 실험에서 사용한 콩은 장류용으로 대원콩, 대풍콩, 새단백콩 및 태광콩(농협하나로마트, 수원) 4 개 품종을 사 용하였고, 발효 균주로는 선행연구에서 선발 된 메밀 속성 장 유래 혈전 용해능과 항균활성이 뛰어난 저영양성 $B$. subtilis HJ18-9를 starter로 사용하였다(19).

청국장은 콩을 정선, 선별 및 세척 후 실온에서 24시간 침지하였고, autoclave(VS-1321-100, Vision Sci. Co., Seoul, Korea $)$ 를 이용하여 증자 $\left(121^{\circ} \mathrm{C}, 50 \mathrm{~min}\right)$ 하였다. 증자된 콩 을 $40^{\circ} \mathrm{C}$ 이하의 온도로 방냉 한 후, 액체배지에 전배양 된 B. subtilis HJ18-9(600 nm, OD 0.5)를 원심분리(8,000 rpm, $10 \mathrm{~min}$ )하여 동일한 양의 saline용액으로 재현탁 한 후, $1 \%$ $\left(\mathrm{w} / \mathrm{w}, 10^{6} \mathrm{CFU} / \mathrm{mL}\right)$ 의 농도로 접종하여 발효 $\left(37^{\circ} \mathrm{C}, 48 \mathrm{hr}\right)$ 하였다.

\section{수분 측정}

수분함량은 $\mathrm{AOAC}$ 법(20)에 따라 $105^{\circ} \mathrm{C}$ 상압건조법에 의해 분석하였다. 시료 $2 \mathrm{~g}$ 을 $105^{\circ} \mathrm{C}$ Dry oven(MOV-112, Sanyo Co., Ltd., Osaka, Japan)에서 항량이 될 때까지 건조시 켜 백분율로 나타내었다.

\section{아미노태 질소 $\left(\mathrm{NO}_{3}-\mathrm{N}\right)$ 측정}

원료콩 및 청국장의 아미노태 질소함량은 Formol 적정법 (21)을 이용하여 측정하였다. 시료 $10 \mathrm{~g}$ 에 증류수를 10 배 가하여 1분 동안 균질화(Homogenizer, Polytron PT-MR 2100, Kinematica AG, Lucerne, Switzerland) 한 후, 1 시간동 안 교반하여 원심 분리( $8,000 \mathrm{rpm}, 10 \mathrm{~min}$, supra $25 \mathrm{k}$, Hanil
Co., Ltd., Incheon, Korea)한 상층액을 시료로 사용하였다. 다. 시료 $5 \mathrm{~mL}$ 에 중성 formalin 용액 $10 \mathrm{~mL}$ 과 증류수 10 $\mathrm{mL}$ 을 넣은 본 시험과 시료액 $5 \mathrm{~mL}$ 에 증류수 $20 \mathrm{~mL}$ 을 넣은 공시험에 $0.1 \mathrm{~N} \mathrm{NaOH}$ 를 이용하여 $\mathrm{pH}$ 8.4로 중화적정하여 아미노태 질소 함량을 산출하였다.

암모니아태 질소 $\left(\mathrm{NH}_{4}-\mathrm{N}\right)$ 측정

원료 콩 및 청국장의 암모니아태 질소함량은 Lee 등(22) 의 방법에 따라 측정하였다. 시료액의 $0.1 \mathrm{~mL}$ 에 $\mathrm{A}$ 용액과 $\mathrm{B}$ 용액을 각각 $2 \mathrm{~mL}$ 씩 넣고 반응 $\left(37^{\circ} \mathrm{C}, 20 \mathrm{~min}\right)$ 한 후, microplate reader(Biotek Synergy Mx, Biotek Instruments, Winooski, VT)를 사용하여 $630 \mathrm{~nm}$ 에서 흡광도를 측정하였 으며, $\left(\mathrm{NH}_{4}\right)_{2} \mathrm{SO}_{4}$ 를 사용하여 작성한 표준곡선을 이용 암모 니아태 질소함량을 산출하였다.

A solution: phenol $10 \mathrm{~g}$ and sodium nitroprusside dehydrate $0.05 \mathrm{~g}$ in distilled water $1,000 \mathrm{~mL}$

B solution: $\mathrm{Na}_{2} \mathrm{HPO}_{4} \cdot 12 \mathrm{H}_{2} \mathrm{O} 9 \mathrm{~g}, \mathrm{NaOH} 6 \mathrm{~g}$ and $\mathrm{NaOCl}$ $10 \mathrm{~mL}$ in distilled water $1,000 \mathrm{~mL}$

\section{유리아미노산 함량 측정}

유리아미노산은 $\operatorname{Kim}$ 등(23)의 방법을 변형하여 측정하 였다. 시료 $5 \mathrm{~g}$ 에 $70 \%$ 에탄올 $100 \mathrm{~mL}$ 을 가하여 균질화화 한 후, 진탕추출 $(180 \mathrm{rpm}, 30 \mathrm{~min}, \mathrm{SK}-71$ Shaker, Jeio Tech, Kimpo, Korea) 하였다. 추출액은 원심분리 $(8,000 \mathrm{rpm}, 10$ $\mathrm{min}$ )하여 상등액을 취하고 남은 잔사에 $70 \%$ 에탄올 50 $\mathrm{mL}$ 을 넣어 재추출한 후 진탕, 원심분리를 반복하여 상층액 모두 합하여 rotary vacuum evaporator(Rotavapor R-205, BUCHI, Flawil, Switzerland)로 감압농축하였다. 농축액은 $70 \%$ 에탄올을 첨가하여 $50 \mathrm{~mL}$ 로 정용하여 시료 용액으로 사용하였다. 시료 용액은 $0.45 \mu \mathrm{m}$ 의 syringe filter로 여과하 여 Waters사의 AccQ-Tag Amino Acid Analysis 방법에 따라 유도체화하였다. 여과액 $10 \mu \mathrm{L}$ 에 AccQ-Fluor Borate Buffer $70 \mu \mathrm{L}$ 를 넣고 잘 혼합한 후, AccQ-Fluor Reagent $20 \mu \mathrm{L}$ 를 가하여 혼합한 다음에 상온에서 1 분간 방치하였다. 이를 Heating Block을 이용하여 $55^{\circ} \mathrm{C}$ 에서 10 분간 가열한 후에 Acquity UPLCR system(Waters, Milford, MA, USA)에 주입 하여 Column(AccQ-TagTMUltraColumn $2.1 \times 100 \mathrm{~mm}$ ), Column temp. $\left(55^{\circ} \mathrm{C}\right)$, Injection volume $(1.0 \mathrm{uL})$, Flow rate $(0.7$ $\mathrm{mL} / \mathrm{min}$ ), Mobile phase(A, Eluent A; B, Eluent B), Detection (UV $260 \mathrm{~nm}$ )의 조건으로 분석하였다.

\section{유기산 측정}

유기산은 In 등(24)의 방법에 따라 측정하였다. 시료액을 취해 $0.45 \mu \mathrm{m}$ membrane filter를 이용하여 여과한 후 여액을 HPLC(NANOSPACE SI-2, Shiseido Co., Ltd., Tokyo, Japan) 를 이용하여 column(Unison UK-C18(250×4.6 mm, $3 \mu \mathrm{m})$ ), 
detector(PDA $214 \mathrm{~nm}$ ), mobile phase(25 mM KH2PO4 pH 2.5), flow $\operatorname{rate}(700 \mu \mathrm{L} / \mathrm{min})$, injectin volume $(20 \mu \mathrm{L})$ 와 같은 조건으로 분석하였다.

\section{단백질 분해 패턴 분석}

단백질 분해 패턴 분석은 sodium dodecylsulfatepolyacrylamide(SDS-PAGE)분석을 실시하였다. 시료액에 SDS-PAGE용 sample buffer(0.05 M Tris- $\mathrm{HCl}$ [pH 6.8], 10\% glycerol, $0.2 \%$ 2-mercaptoethanol, $2 \%$ SDS, $0.1 \%$ bromophenolblue) 를 첨가한 후, 가열 $\left(100^{\circ} \mathrm{C}, 5 \mathrm{~min}\right)$ 하여 단백질 변성을 유도한 후 전기영동을 하였다. Sample buffer에 녹은 단백질을 $12 \%$ separating gel로 이루어진 disc SDS-PAGE mini-gel(BioRad, Hercules, CA, USA)에 시료를 넣고 전기영동 $(100 \mathrm{~V}, 90$ $\mathrm{min}$ ) 하였다. 전기영동이 끝나면 gel에 분리된 단백질 bands 를 coomassie brilliant blue(CBB)로 염색하고 coomassie brilliant blue destaining 용액으로 탈색하여 단백질 분해 패 턴을 분석하였다.

\section{총균수 측정}

생균수 측정은 청국장 $1 \mathrm{~g}$ 을 멸균생리식염수로 단계 희 석하고 plate count agar(Difco Lab. Detroit, MI, USA) 평판배 지에 도말하여 $37^{\circ} \mathrm{C}$ 에서 24시간 배양시킨 후 나타난 colony 를 계수하여 총균수를 측정하였다.

\section{통계 분석}

실험결과는 3회 반복으로 측정하였으며, 평균치간의 유 의성 검증은 SPSS system(Statistical Pack-age for Social Sciences, SPSS Inc, Chicago, IL, USA) soft-ware package (version 12)를 이용, $\mathrm{p}<0.05$ 수준으로 Duncan's multiple range test에 의하여 검정하였다.

\section{결과 및 고찰}

수분함량

수분함량은 Table 1에 나타내었다. 원료콩의 경우 $62.45 \sim 67.12 \%$ 의 범위였으며, 품종별 수분함량은 대풍, 태

Table 1. Moisture content of soybean and Chunggukjang prepared with various soybean cultivars

\begin{tabular}{ccccc}
\hline$\%$ & $\mathrm{~A}^{1)}$ & $\mathrm{B}$ & $\mathrm{C}$ & $\mathrm{D}$ \\
\hline $\mathrm{a}^{2)}$ & $64.04 \pm 0.23^{\mathrm{Bb} 3)}$ & $67.12 \pm 0.11^{\mathrm{Aa}}$ & $62.45 \pm 0.29^{\mathrm{Cb}}$ & $67.00 \pm 0.67^{\mathrm{Aa}}$ \\
$\mathrm{c}$ & $66.34 \pm 0.48^{\mathrm{ABa}}$ & $64.94 \pm 0.87^{\mathrm{Bb}}$ & $63.28 \pm 0.77^{\mathrm{Cab}}$ & $67.14 \pm 0.95^{\mathrm{Aa}}$ \\
$\mathrm{t}$ & $66.87 \pm 0.61^{\mathrm{Aa}}$ & $64.57 \pm 0.30^{\mathrm{Bb}}$ & $64.50 \pm 0.89^{\mathrm{Ba}}$ & $64.67 \pm 0.29^{\mathrm{Bb}}$ \\
\hline
\end{tabular}

${ }^{1)}$ A, Daewon; B, Deapung; C, Seadanbeak; D, Taekwang.

${ }^{2)}$ a, soybean; c, conventional Chunggukjang, $\mathrm{t}$, Chunggukjang fermented with B. subtilis HJ18-9.

${ }^{3}$ Any means in the same column (A-B) or row (a-d) followed by different letters are significantly $(\mathrm{p}<0.05)$ different by Duncan's multiple range test.
광, 대원, 새단백 순으로 높게 나타났다. stater를 첨가하지 않은 전통방법으로 제조한 청국장(청국장c)과 starter를 첨 가하여 제조한 청국장(청국장t)의 수분함량은 63.28 67.14 $\%$ 와 64.50 66.87\%로 나타났다. 전통청국장 $(25)$ 의 수분함 량은 평균 $57.0 \pm 3.1 \%$ 로 보고된 바 있으며, 발아시킨 콩으로 제조한 청국장(26)의 경우 $64.2 \%, 65.0 \%$ 로 본 시료와 유사 하였다. 이는 청국장의 증자 후, 방냉과정과 발효조건에 따라 차이를 보이는 것으로 보인다.

\section{아미노태 질소 함량}

아미노태 질소함량은 Table 2에 나타내었다. 원료콩(a)의 경우 6.53 24.25 mg\%로 대원, 새단백, 대풍, 태광의 순서로 나타났다. 청국장 $\mathrm{c}$ 는 $27.63 \sim 122.09 \mathrm{mg} \%$, 청국장 $\mathrm{t}$ 는 $37.29 \sim 133.48 \mathrm{mg} \%$ 범위를 나타내었다. 그 중 새단백으로 제조한 청국장의 아미노태 질소함량이 가장 높은 값을 나타 내었고 태광, 대풍, 대원으로 제조한 청국장 순서로 나타났 다. 새단백은 단백질 함량이 $48 \%$ 이상으로 일반 콩 $(40 \%)$ 보 다 많은 단백질을 함유하고 있다. 청국장(t)의 경우 청국장 (c)보다 높은 아미노태 질소 값을 나타내어, 미생물 유래 단백질 분해효소로 인해 대두 단백질이 가수분해 되어 아미 노산으로 더 많이 분해된 것을 알 수 있었다(27). 볏짚을 이용한 청국장 연구(28)에 따르면 48시간 발효한 청국장의 경우 $169.8 \mathrm{mg} \%$ 로 본 시료와 차이를 보였다. 이는 보통 볏집에는 Bacillus 뿐만 아니라 다양한 유산균 등 다양한 균이 분포되어 있고, 존재하는 미생물의 양에 따라 다른 발효양상을 보인 것으로 생각된다. 우수한 starter가 단백질 이 풍부한 발효원이 접종되면, 발효효율 및 유용성분이 많 아질 것으로 사료된다.

Table 2. Amino-type nitrogen content of soybean and Chunggukjang prepared with various soybean cultivars and $B$. subtilis $\mathrm{HJ} 18-9$

\begin{tabular}{ccccc}
\hline $\mathrm{mg} \%$ & $\mathrm{~A}^{1)}$ & $\mathrm{B}$ & $\mathrm{C}$ & $\mathrm{D}$ \\
\hline $\mathrm{a}^{2)}$ & $7.46 \pm 4.27^{\mathrm{Bc} 3)}$ & $24.25 \pm 1.61^{\mathrm{Ac}}$ & $12.13 \pm 4.28^{\mathrm{Bc}}$ & $6.53 \pm 4.27^{\mathrm{Bc}}$ \\
$\mathrm{c}$ & $27.63 \pm 5.53^{\mathrm{Cb}}$ & $36.16 \pm 2.80^{\mathrm{Cb}}$ & $122.09 \pm 4.94^{\mathrm{Ab}}$ & $47.45 \pm 5.51^{\mathrm{Bb}}$ \\
$\mathrm{t}$ & $37.29 \pm 1.33^{\mathrm{Da}}$ & $45.66 \pm 7.19^{\mathrm{Ca}}$ & $133.48 \pm 2.78^{\mathrm{Aa}}$ & $74.64 \pm 0.18^{\mathrm{Ba}}$ \\
\hline
\end{tabular}

${ }^{1)}$ A, Daewon; B, Deapung, C, Seadanbeak; D, Taekwang.

2) a, soybean; c, conventional Chunggukjang, t, Chunggukang fermented with $B$. subtilis HJ18-9.

${ }^{3)}$ Any means in the same column (A-B) or row (a-d) followed by different letters are significantly $(\mathrm{p}<0.05)$ different by Duncan's multiple range test.

암모니아태 질소 함량

암모니아태 질소함량은 Table 3와 같다. 원료콩의 경우 $26.92 \sim 47.95 \mathrm{mg} \%$ 의 범위였으며, 대원, 새단백, 태광, 대풍 순이었다. 청국장 $\mathrm{c}$ 는 $45.45 ~ 156.36 \mathrm{mg} \%$, 청국장 $\mathrm{t}$ 는 $28.02 \sim 121.13 \mathrm{mg} \%$ 로 나타났다. 그 중 새단백이 가장 높은 값을 나타내었고 대원, 태광, 대풍으로 제조한 청국장순으 로 낮은 값을 나타내었다. 아미노태 질소와는 반대로 청국 
장 $\mathrm{c}$ 의 경우, 청국장 $\mathrm{t}$ 보다 낮은 암모니아태 질소함량을 나타내어, 청국장 c는 단백질의 과도한 분해로 인해 더 많은 암모니아태질소를 생성하여 품질을 저하시킨 것을 알 수 있었다(29). 장류발효 균주를 이용한 청국장(30)에 따르면 암모니아태가 63 154 mg\%를 나타내어 본 실험과 유사한 것을 알 수 있었다. 자연 발효에 의한 발효의 경우, 다양한 미생물이 발효에 관여하게 되는 반면, 균을 접종한 경우, 접종 된 균주가 우점종이 되어 단일을 미생물분포를 나타내 고, 이러한 미생물분포는 청국장 품질특성에 각각 다른 영 향을 미치게 된다.

Table 3. Ammonia-type nitrogen content of soybean and Chunggukjang prepared with various soybean cultivars and $B$. subtilis HJ18-9

\begin{tabular}{ccccc}
\hline $\mathrm{mg} \%$ & $\mathrm{~A}^{1)}$ & $\mathrm{B}$ & $\mathrm{C}$ & $\mathrm{D}$ \\
\hline $\mathrm{a}^{2)}$ & $47.95 \pm 8.91^{\mathrm{Ac} 3)}$ & $26.92 \pm 1.12^{\mathrm{Cb}}$ & $47.36 \pm 0.99^{\mathrm{Ac}}$ & $36.44 \pm 1.75^{\mathrm{Bb}}$ \\
$\mathrm{c}$ & $117.79 \pm 7.43^{\mathrm{Ba}}$ & $45.45 \pm 1.86^{\mathrm{Ca}}$ & $156.36 \pm 6.45^{\mathrm{Aa}}$ & $54.57 \pm 4.48^{\mathrm{Ca}}$ \\
$\mathrm{t}$ & $67.18 \pm 4.73^{\mathrm{Bb}}$ & $28.02 \pm 0.91^{\mathrm{Db}}$ & $121.13 \pm 6.43^{\mathrm{Ab}}$ & $40.19 \pm 1.26^{\mathrm{Cb}}$ \\
\hline
\end{tabular}

${ }^{1)}$ A, Daewon; B, Deapung; C, Seadanbeak; D, Taekwang.

2), soybean; c, conventional Chungoukjang, t, Chungoukjang fermented with $B$. subtilis HJ18-9.

${ }^{3)}$ Any means in the same column (A-B) or row (a-d) followed by different letters are significantly $(\mathrm{p}<0.05)$ different by Duncan's multiple range test.
유리 아미노산 함량

유리아미노산 함량 측정결과는 Table 4에 나타내었다. 원료콩과 청국장 $\mathrm{c}$ 에서는 glutamic acid가 높은 함량을 보였 고, 청국장 $\mathrm{t}$ 중에서 대원콩 $(7.85 \pm 0.51 \mathrm{mg} \%)$ 과 대풍콩 $(11.14 \pm 0.63 \mathrm{mg} \%)$ 으로 제조한 청국장에서는 phenylalanine, 새단백 $(20.21 \pm 0.56 \mathrm{mg} \%)$ 과 태광콩 $(10.04 \pm 0.49 \mathrm{mg} \%)$ 으로 제조한 청국장에서는 glutamic acid이 높은 함량을 나타내 었다. 감칠맛과 쓴맛에 관여하는 주요 아미노산의 프로파 일을 Fig. 1 및 Fig. 2에 나타내었다. 감칠맛(glutamic acid 및 aspartic acid)의 양은 새단백의 경우, 원료콩( $13.82 \pm 0.34$ $\mathrm{mg} \%)$, 청국장 $\mathrm{c}(31.83 \pm 0.31 \mathrm{mg} \%)$, 청국장 $\mathrm{t}(20.71 \pm 0.60$ $\mathrm{mg} \%$ )으로 원료콩 보다 발효 시, 감칠맛 성분이 증가하였으 며, 대원, 대풍, 태광의 경우, 원료콩 및 청국장 상태에서 큰 차이를 보이지 않았다. 쓴맛(valine, methionine, isoleucine, leucine 및 phenylalanine)은 콩보다 청국장에서 많은 양이 검출되어 균이 생성하는 단백질 분해 효소에 의해 단백질이 분해되면서 단맛을 내는 아미노산에 비해 쓴맛 아미노산이 더 유리된 것을 알 수 있었다(31). Bacillus sp. CS-17을 이용한 청국장(32)에서는 발효 48시간 후 phenylalanine이 가장 많이 함유되었고, leucine, lysine순이 었다고 보고하였고, Bacillus sp. DC-2균을 이용하여 제조한 청국장(33)에서는 glutamic acid가 가장 많이 검출 되었고, phenylalanine, alanine 순으로 나타났다고 하였으며, 이는

Table 4. Free amino acid content of soybean and Chunggukjang prepaared with various soybean cultivars and B. subtilis HJ18-9

\begin{tabular}{|c|c|c|c|c|c|c|c|c|c|c|c|c|}
\hline $\mathrm{mg} \%$ & $\mathrm{Aa}^{1)}$ & $\mathrm{Ac}$ & At & $\mathrm{Ba}$ & $\mathrm{Bc}$ & $\mathrm{Bt}$ & $\mathrm{Ca}$ & $\mathrm{Cc}$ & $\mathrm{Ct}$ & $\mathrm{Da}$ & $\mathrm{Dc}$ & Dt \\
\hline His & $0.63 \pm 0.06^{(\mathrm{c} 2)}$ & 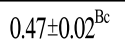 & $1^{\mathrm{Ba}}$ & $30 \pm 0.02^{\mathrm{Dc}}$ & $.57 \pm 0.04^{\mathrm{Bb}}$ & $90 \pm 0.06^{\mathrm{Ba}}$ & $2.70 \pm 0.19^{\mathrm{Aa}}$ & $.35 \pm 0.16^{\mathrm{Ab}}$ & $1.43 \pm 0.24^{\mathrm{Ab}}$ & 110 & $.03 \pm 0.00^{\mathrm{cb}}$ & $.01 \pm 0.00^{\mathrm{Cb}}$ \\
\hline Ser & & & & & & & & & & & & \\
\hline $\operatorname{Arg}$ & $5.29 \pm 0.01^{\mathrm{Aa}}$ & $34 \pm 0.07^{\mathrm{BC}}$ & $0.65 \pm 0.11^{\mathrm{Cb}}$ & $1+00^{\mathrm{Ba}}$ & $0.45 \pm 0.02^{\mathrm{BC}}$ & $0.93 \pm 0.00^{\mathrm{Bb}}$ & $2.15 \pm 0.18^{\mathrm{Ca}}$ & $1.59 \pm 0.15^{\mathrm{Ab}}$ & $1.13 \pm 0.03^{\mathrm{Ac}}$ & $5.51 \pm 0.22^{\mathrm{Aa}}$ & $0.17 \pm 0.02^{\mathrm{Cc}}$ & $0.47 \pm 0.04^{\mathrm{Db}}$ \\
\hline Gly & & & & & & & & & $0.67 \pm 0.07^{\mathrm{Bb}}$ & & & \\
\hline Asp & & & $0.76 \pm 0.05^{\mathrm{Bc}}$ & $3.56 \pm 0.02^{\mathrm{Da}}$ & $0.63 \pm 0.03^{\mathrm{Cc}}$ & $1.06 \pm 0.11^{\mathrm{Ab}}$ & $5.91 \pm 0.11^{\mathrm{Aa}}$ & $0.78 \pm 0.04^{\mathrm{Bb}}$ & $0.50 \pm 0.03^{\mathrm{Cc}}$ & $3.92 \pm 0.10^{\mathrm{Ca}}$ & $0.13 \pm 0.02^{\mathrm{Db}}$ & $0.04 \pm 0.00^{\mathrm{Da}}$ \\
\hline Glu & & & $7.31 \pm 0.03^{\mathrm{Ca}}$ & & $8.28 \pm 0$ & $6.80 \pm 0.03^{\mathrm{cb}}$ & & & & & & \\
\hline Thr & & $0.66 \pm 0.00^{\mathrm{Db}}$ & $1.03 \pm 0.00^{\mathrm{Ca}}$ & $0.34 \pm 0.02^{\mathrm{Dc}}$ & $0.84 \pm 0.01^{\mathrm{Cb}}$ & $1.48 \pm 0.02^{\mathrm{Aa}}$ & $0.86 \pm 0.07^{\mathrm{Ac}}$ & $1.37 \pm 0.12^{A \mathrm{a}}$ & $1.18 \pm 0.06^{\mathrm{Bb}}$ & $0.76 \pm 0.05^{\mathrm{Bc}}$ & $1.11 \pm 0.04^{\mathrm{Bb}}$ & $1.30 \pm 0.12^{\mathrm{BC}}$ \\
\hline Ala & $3.06 \pm 0.09^{\mathrm{Cb}}$ & $2.88 \pm 0.11^{\mathrm{Cc}^{c}}$ & $3.75 \pm 0.04^{\mathrm{Ba}}$ & $1.66 \pm 0.03^{\mathrm{Dc}}$ & $4.08 \pm 0.10^{\mathrm{Bb}}$ & $4.61 \pm 0.16^{\mathrm{Ag}}$ & $3.58 \pm 0.25^{\mathrm{Bb}}$ & $4.45 \pm 0.38^{\mathrm{Ba}}$ & $3.73 \pm 0.39^{\mathrm{Bb}}$ & $4.07 \pm 0.18^{A b}$ & $5.10 \pm 0.04^{\mathrm{Aa}}$ & $3.55 \pm 0.37^{\mathrm{Ba}}$ \\
\hline Pro & $1.08 \pm 0.02^{\mathrm{Ac}}$ & $1.36 \pm 0.04^{\mathrm{BCb}}$ & $1.69 \pm 0.07^{\mathrm{Aa}}$ & $0.68 \pm 0.04^{\mathrm{Bb}}$ & $1.55 \pm 0.06^{\mathrm{ABa}}$ & $1.63 \pm 0.21^{\mathrm{Aa}}$ & $1.20 \pm 0.16^{\mathrm{Aa}}$ & $1.34 \pm 0.10^{\mathrm{Ca}}$ & $1.34 \pm 0.14^{\mathrm{Ba}}$ & $1.12 \pm 0.06^{\mathrm{Ab}}$ & $1.71 \pm 0.16^{\mathrm{Aa}}$ & $1.53 \pm 0.12^{\mathrm{ABa}}$ \\
\hline Cys & $0.10 \pm 0.02^{\mathrm{Aa}}$ & $0.04 \pm 0.01^{\mathrm{Bb}}$ & $0.09 \pm 0.02^{\mathrm{Ba}}$ & $0.00 \pm 0.00^{\mathrm{Bb}}$ & $0.00 \pm 0.00^{\mathrm{Cb}}$ & $0.30 \pm 0.18^{\mathrm{Ag}}$ & $0.00 \pm 0.00^{\mathrm{Bb}}$ & $0.10 \pm 0.01^{\mathrm{Aa}}$ & $0.10 \pm 0.02^{\mathrm{Ba}}$ & $0.00 \pm 0.00^{\mathrm{cb}}$ & $0.10 \pm 0.02^{\mathrm{Aa}}$ & $0.10 \pm 0.02^{\mathrm{Ba}}$ \\
\hline Lys & & & & & & & & & $1.86 \pm 0.01^{\mathrm{Cb}}$ & & $2.17 \pm 0.32^{\mathrm{Bc}}$ & \\
\hline Tyr & $1.59 \pm 0.03^{\mathrm{Ba}}$ & $0.67 \pm 0.00^{B b}$ & $0.68 \pm 0.02^{\mathrm{Cb}}$ & $1.16 \pm 0.02^{\mathrm{Ca}}$ & $0.50 \pm 0.02^{\mathrm{Cc}}$ & $0.86 \pm 0.02^{\mathrm{Bb}}$ & $2.02 \pm 0.08^{\mathrm{Ab}}$ & $3.14 \pm 0.00^{\mathrm{Ag}}$ & $1.46 \pm 0.10^{\mathrm{Ac}}$ & $1.60 \pm 0.08^{\mathrm{Ca}}$ & $0.49 \pm 0.05^{\mathrm{Cb}}$ & $0.59 \pm 0.08^{\mathrm{Cb}}$ \\
\hline Met & & & & & & & & & & & & \\
\hline $\mathrm{Val}$ & $1.64 \pm 0.18^{\mathrm{Ac}}$ & $2.63 \pm 0.52^{\mathrm{Cb}}$ & $4.85 \pm 0.00^{\mathrm{Ba}}$ & $0.61 \pm 0.09^{\mathrm{BC}}$ & $3.97 \pm 0.32^{\mathrm{Bb}}$ & $5.80 \pm 0.16^{\mathrm{Aa}}$ & $1.50 \pm 0.08^{\mathrm{Ab}}$ & $4.62 \pm 0.16^{\mathrm{Aa}}$ & $4.61 \pm 0.16 \mathrm{~B}^{\mathrm{Ca}}$ & $1.40 \pm 0.15^{\mathrm{Ac}}$ & & $4.47 \pm 0.21^{\mathrm{Ca}}$ \\
\hline Ile & $0.83 \pm 0.00^{\mathrm{Ac}}$ & $1.44 \pm 0.04^{\mathrm{Db}}$ & $2.57 \pm 0.18^{\mathrm{Ba}}$ & $0.32 \pm 0.02^{\mathrm{Bc}}$ & $2.08 \pm 0.19^{\mathrm{Bb}}$ & $3.24 \pm 0.13^{\mathrm{Aa}}$ & $0.78 \pm 0.11^{\mathrm{Ab}}$ & $2.98 \pm 0.21^{\mathrm{Aa}}$ & $3.03 \pm 0.20^{\mathrm{Aa}}$ & $0.84 \pm 0.05^{\mathrm{Ac}}$ & $1.75 \pm 0.08^{\mathrm{Cb}}$ & $2.59 \pm 0.23^{\mathrm{Ba}}$ \\
\hline Leu & $1.19 \pm 0.06^{\mathrm{Bc}}$ & $4.26 \pm 0.32^{\mathrm{Db}}$ & $7.15 \pm 0.56^{\mathrm{Ba}}$ & $0.48 \pm 0.01^{\mathrm{Dc}}$ & $6.77 \pm 0.30^{B b}$ & $10.51 \pm 0.54^{\mathrm{Aa}}$ & $0.91 \pm 0.00^{\mathrm{Cc}}$ & $8.38 \pm 0.11^{\mathrm{Aa}}$ & $7.63 \pm 0.12^{\mathrm{Bb}}$ & $1.38 \pm 0.05^{\mathrm{Ac}}$ & & $7.25 \pm 0.24^{\mathrm{Ba}}$ \\
\hline Phe & $1.96 \pm 0.15^{\mathrm{Bc}}$ & $5.11 \pm 0.37^{\mathrm{Cb}}$ & $7.85 \pm 0.51^{\mathrm{Ca}}$ & $1.26 \pm 0.08^{\mathrm{Cc}}$ & $7.61 \pm 0.58^{\mathrm{Bb}}$ & $11.14 \pm 0.63^{\mathrm{Aa}}$ & $2.27 \pm 0.04^{\mathrm{Ac}}$ & $9.42 \pm 0.17^{\mathrm{Ab}}$ & $9.86 \pm 0.00^{\mathrm{Ba}}$ & $2.43 \pm 0.04^{\mathrm{Ab}}$ & $7.87 \pm 0.03^{\mathrm{Ba}}$ & $7.98 \pm 0.12^{\mathrm{Ca}}$ \\
\hline Total & & & & & & 7.19 & 7.56 & 76.49 & & & 39.79 & 45.51 \\
\hline
\end{tabular}

${ }^{11}$ A, Daewon, B, Deapung, C, Seadanbeak, D, Taekwang, a, soybean; c, conventional Chunggukjang, t, Chunggukjang fermented with B. subtilis HJ18-9.

${ }^{2)}$ Any means in the same soybean state (A-B) or soybean cultivars (a-d) followed by different letters are significantly $(\mathrm{p}<0.05)$ different by Duncan's multiple range test. 


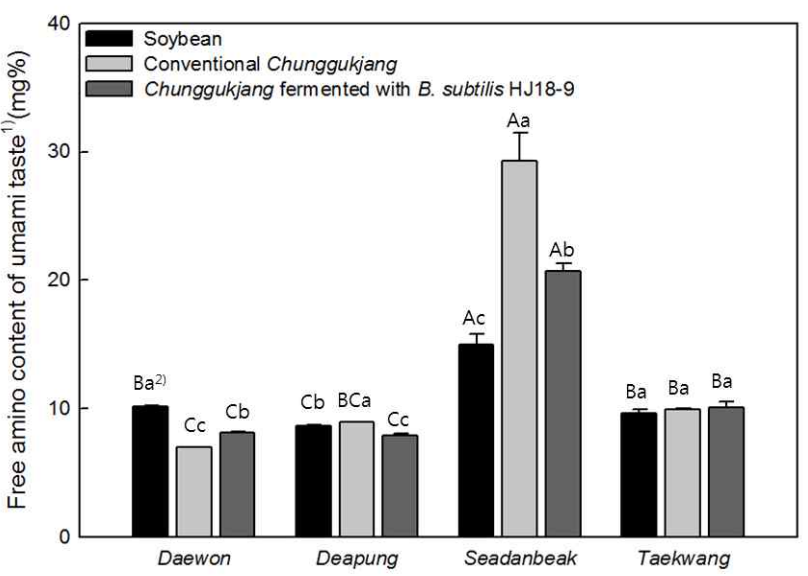

Fig. 1. Free amino acids content in soybean and Chunggukjang based on senses of umami taste.

${ }^{1)}$ Glutamic acid, Aspartic acid.

${ }^{2)}$ Any means in the same soybean state (A-B) or soybean cultivars (a-d) followed by different letters are significantly $(\mathrm{p}<0.05)$ different by Duncan's multiple range test.

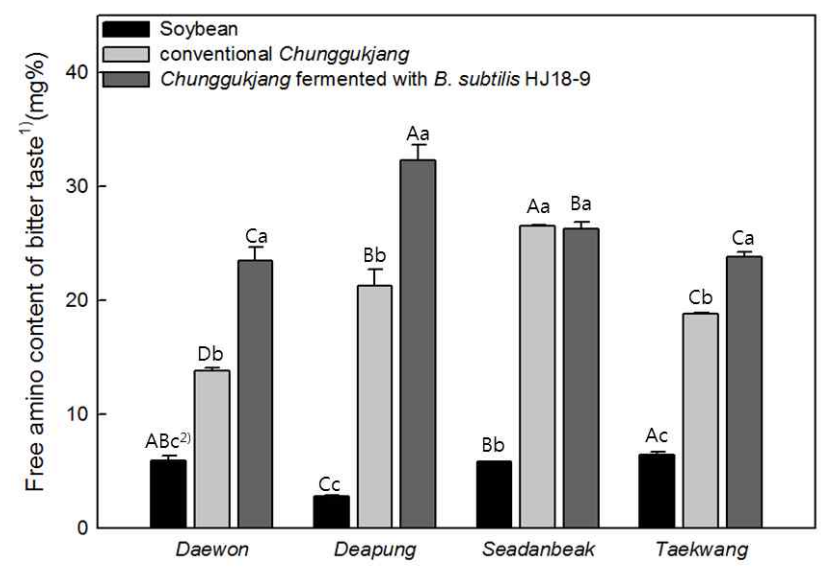

Fig. 2. Free amino acids content in soybean and Chunggukjang based on senses of bitter taste.

${ }^{1}$ Valine, Methionine, Isoleucine, Leucine, Phenylalanine.

${ }^{2)}$ Any means in the same soybean state (A-B) or soybean cultivars (a-d) followed by different letters are significantly $(\mathrm{p}<0.05)$ different by Duncan's multiple range test.

본 실험과 일부 유사한 경향을 보였다. Park 등(34)은 청국 장에 접종되는 균주에 따라 최종제품의 구수한 맛, 쓴맛, 그리고 단맛을 내는 아미노산의 함량이 변하고 이를 이용하 여 청국장의 맛을 조정 할 수 있을 것이라고 보고하였다.

\section{유기산 함량}

유기산 함량 측정결과는 Table 5에 나타내었다. 대풍, 새단백, 태광 원료콩의 경우, succinic $\operatorname{acid}(1,895 \sim 2,121$ $\mathrm{mg} \%$ )가 가장 높은 함량을 나타내었고, 다음으로 citric $\operatorname{acid}(614 \sim 822 \mathrm{mg} \%)$, acetic $\operatorname{acid}(156 \quad 306 \mathrm{mg} \%)$ 순이었다. 청 국장의 경우 starter 첨가 유무에 상관없이 lactic acid (163 896 mg\%)가 가장 높은 함량을 나타내었고, 청국장 t는 청국장 c에 비해 oxalic acid, malic acid, acetic acid가
더 높은 함량을 보였다. 원료 콩에서 청국장으로 발효되면 서 oxalic acid, citric acid와 succinic acid의 경우 그 함량이 감소하였고, malic acid, lactic acid와 acetic acid는 그 함량이 증가하였다. citric acid는 원료콩에 많이 함유 되어 있지만 청국장 관련 미생물의 에너지원으로 이용되면서 급격히 감소되고, lactic acid의 경우 내염성 젖산균에 의해 생성되 는 것으로 추측되며, acetic acid의 경우 Bacillus 의 작용으로 증가되는 것으로 보고되었다(35). 생약초를 첨가한 청국장 (36)의 경우 lactic acid가 가장 높았으며, acetic acid, succinic acid, citric acid 순으로 나타나 본 연구와 유사한 결과를 보였다.

Table 5. Organic acid content of soybean and Chunggukjang prepared with various soybean cultivars

\begin{tabular}{|c|c|c|c|c|c|c|c|}
\hline \multicolumn{2}{|c|}{$\mathrm{mg} \%$} & $\begin{array}{c}\text { Oxalic } \\
\text { acid }\end{array}$ & Malic acid & $\begin{array}{l}\text { Lactic } \\
\text { acid }\end{array}$ & $\begin{array}{c}\text { Acetic } \\
\text { acid }\end{array}$ & Citric acid & $\begin{array}{l}\text { Succinic } \\
\text { acid }\end{array}$ \\
\hline \multirow{3}{*}{$A^{1)}$} & $a^{2)}$ & 51.46 & 69.72 & 66.92 & 117.02 & 915.76 & 224.89 \\
\hline & c & 24.04 & 137.45 & 896.65 & 224.37 & 319.22 & 455.43 \\
\hline & $\mathrm{t}$ & 30.85 & 178.31 & 769.64 & 245.32 & 219.41 & 341.23 \\
\hline \multirow{3}{*}{ B } & $\mathrm{a}$ & 44.34 & 108.52 & 38.86 & 306.21 & 822.41 & 1895.76 \\
\hline & $\mathrm{c}$ & 27.10 & 136.45 & 740.25 & 355.78 & 255.84 & 439.21 \\
\hline & $\mathrm{t}$ & 32.60 & 139.02 & 632.19 & 498.62 & 87.81 & 219.26 \\
\hline \multirow{3}{*}{ C } & $\mathrm{a}$ & 42.82 & 86.27 & 38.37 & 156.26 & 616.57 & 2002.37 \\
\hline & c & 14.00 & 154.26 & 590.79 & 367.26 & 239.10 & 297.55 \\
\hline & $\mathrm{t}$ & 17.14 & 208.41 & 577.57 & 329.32 & 170.69 & 222.99 \\
\hline \multirow{3}{*}{ D } & $\mathrm{a}$ & 19.57 & 127.58 & 113.11 & 213.55 & 614.94 & 2121.17 \\
\hline & c & 15.19 & 142.43 & 660.79 & 267.18 & 154.18 & 261.15 \\
\hline & $t$ & 22.86 & 145.46 & 463.70 & 283.30 & 26.99 & 217.81 \\
\hline
\end{tabular}

${ }^{11}$ A, Daewon; B, Deapung; C, Seadanbeak; D, Taekwang.

2), soybean; c, conventional Chunggukjang, t, Chunggukjang fermented with B. subtilis HJ18-9.

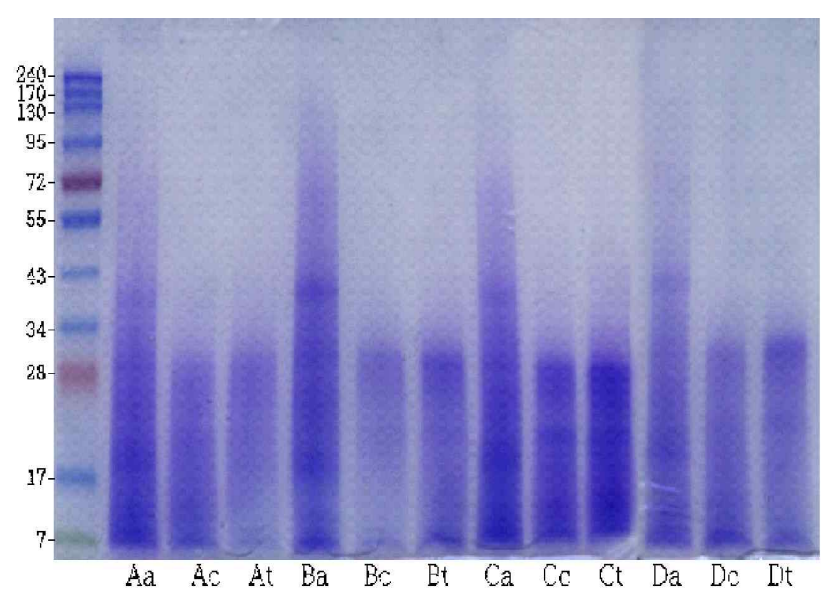

Fig. 3. Analysis of soybean and Chunggukjang protein by SDS-page. A, Daewon; B, Deapung; C, Seadanbeak; D, Taekwang; a, soybean; c, conventional Chunggukjang, $\mathrm{t}$, Chunggukjang fermented with $B$. subtilis HJ18-9. 
단백질 분해 패턴 분석

콩 품종별 starter첨가 유무에 따른 청국장의 SDS-PAGE 분석 결과를 Fig. 1에 나타내었다. 발효전 원료콩의 주된 단백질은 7 43 KDa인 반면 청국장 $\mathrm{c}$ 와 청국장 $\mathrm{t}$ 의 주된 단백질은 7 28 KDa로 나타났다. 이는 발효에 의해 고분자 의 단백질이 분해되어 작은 분자량의 단백질이 증가하는 것을 확인할 수 있었다. 홍삼을 이용한 청국장(14)의 경우, $33 \mathrm{KDa}$ 이하의 단백질로 분해되었으며, 특히 $11 \mathrm{KDa}$ 크기 의 단백질이 주를 이루었으며, B. licheniformis $\mathrm{B} 1$ 을 이용한 청국장(37)의 경우 증자대두에서는 $66 \mathrm{KDa}$ 이상의 분자량 을 보였지만 발효가 시작되면서 작은 분자량이 증가하여 24 시간 후에는 $36 \mathrm{KDa}$ 이하로 감소하여 본 연구와 유사한 결과를 보였다. 새단백 청국장의 경우, $20 \mathrm{KDa}$ 에 원료콩에 서는 관찰되지 않은 새로운 밴드가 확인되어 추후, 물질동 정을 통한 확인이 필요할 것으로 사료된다.

\section{총 균수}

콩 품종별 starter첨가 유무에 따른 청국장의 총 균수의 변화는 Table 6에 나타내었다. 원료콩의 경우 3.80 5.67 log $\mathrm{CFU} / \mathrm{mL}$ 의 범위였으며, 태광, 새단백, 대원, 대풍 순이었다. 청국장(c)은 7.48 8.85 $\log \mathrm{CFU} / \mathrm{mL}$, 청국장 $(\mathrm{t})$ 은 7.86 8.46 $\log \mathrm{CFU} / \mathrm{mL}$ 로 나타났다. 단백질 분해정도의 주요요소는 미생물의 종류 및 양인데, 청국장 c는 Bacillus외에 유산균 등 다양한 세균이 관여하게 되어 단일균으로 제조된 청국장 $\mathrm{t}$ 와는 다른 발효양상을 보일 수 있다. $\mathrm{Ju}$ 등(38)에 따르면 B. subtilis을 접종하였을 경우 B. subtilis의 빠른 생육이 유산 균과 같은 다른 균의 생육을 억제한다고 보고하였으며 발아 콩을 이용한 청국장의 총균수는 $10^{8} \sim 10^{9} \mathrm{CFU} / \mathrm{mL}$ 로 본 연구 와 유사한 결과를 보였다(39).

Table 6. Aerobic bacterial counts of soybean and Chunggukjang prepared with various soybean cultivars

\begin{tabular}{ccccc}
\hline Log CFU/mL & $\mathrm{A}^{1)}$ & $\mathrm{B}$ & $\mathrm{C}$ & $\mathrm{D}$ \\
\hline $\mathrm{a}^{2)}$ & $5.15 \pm 0.25^{\mathrm{ABb} 3)}$ & $5.67 \pm 0.30^{\mathrm{Ac}}$ & $4.49 \pm 0.69^{\mathrm{BCb}}$ & $3.80 \pm 0.17^{\mathrm{Cc}}$ \\
$\mathrm{c}$ & $8.68 \pm 0.07^{\mathrm{Ba}}$ & $8.85 \pm 0.04^{\mathrm{Aa}}$ & $8.14 \pm 0.09^{\mathrm{Da}}$ & $8.29 \pm 0.01^{\mathrm{Ca}}$ \\
$\mathrm{t}$ & $8.46 \pm 0.03^{\mathrm{Aa}}$ & $8.19 \pm 0.03^{\mathrm{ABb}}$ & $7.48 \pm 0.34^{\mathrm{Ca}}$ & $7.86 \pm 0.05^{\mathrm{Bb}}$ \\
\hline
\end{tabular}

\footnotetext{
${ }^{1)} \mathrm{A}$, Daewon; B, Deapung; C, Seadanbeak; D, Taekwang.

a, soybean; c, conventional Chungoukjang, t, Chunggukjang fermented with B. subtilis HJ18-9.

${ }^{3)}$ Any means in the same column (A-B) or row (a-d) followed by different letters are significantly $(\mathrm{p}<0.05)$ different by Duncan's multiple range test.
}

\section{요 약}

본 연구는 장류용 주요 콩 품종별, 유용발효미생물인 Bacillus subtilis HJ18-9 첨가 유무에 따른 청국장의 이화학 적인 특징과 맛에 관여하는 아미노산 및 유기산 구성을
비교하고자 하였다. 원료콩 으로는 대원, 대풍, 새단백, 태 광을 사용하였다. 원료콩(찐콩), starter를 첨가하지 않은 전 통방법으로 제조한 청국장(청국장 c)과 starter를 첨가하여 제조한 청국장(청국장 $\mathrm{t}$ )의 수분함량은 62.45 67.12, 63.28 $67.14,64.50 \sim 66.87 \%$ 이었으며, 아미노태 질소는 6.53 24.25, 27.63 122.09, 37.29 133.48 mg\%, 암모니아태 질소는 26.92 $47.95,45.45 \sim 156.36,28.02 \sim 121.13 \mathrm{mg} \%$ 로 나타났다. 유리 아미노산 함량은 원료콩이 청국장보다 감칠맛을 내는 glutamic acid, aspartic acid이 더 많은 반면, 쓴맛을 내는 valine, methionine, isoleucine, leucine, phenylalanine은 starter 첨가 유무에 관계없이 청국장이 원료콩보다 더 많은 양이 검출되었다. 유기산은 원료 콩에서 청국장으로 발효 되면서 oxalic acid와 citric acid의 경우 그 함량이 감소하였 고, malic acid, lactic acid, acetic acid, succinic acid는 그 함량이 증가하였다. SDS-page 확인 결과 원료콩에서는 넓 은 분포로 band가 보였지만 청국장의 경우 분자량이 큰 단백질이 사라지고 작은 분자량이 증가하는 것을 확인할 수 있었다. 총 균수는 원료콩, 청국장 $\mathrm{c}$ 및 청국장 $\mathrm{t}$ 의 경우, 각각 3.80 5.67, 8.14 8.85, 7.48 8.46 $\log \mathrm{CFU} / \mathrm{mL}$ 의 범위로 나타났다. 이상의 결과로 콩품종에 따라 발효정도에 차이 를 보이는 것과, starter첨가에 따른 품종별 발효양상이 다른 것을 확인하게 되었다. 특히, starter첨가 시, 다른 품종에 비해 새단백 청국장의 감칠맛과 연관된 glutamic acid와 aspartic acid의 함량이 증가하는 것으로 보아 주로 두부제조 용으로 이용되었던 새단백의 용도다양화가 가능 할 것으로 판단된다. 본 내용은 콩품종 및 starter 첨가에 따른 청국장 의 이화학적인 특징과 맛에 관여하는 아미노산 및 유기산 구성을 비교하여 청국장의 품질을 향상시키는데 필요한 기초자료로써 향후, 기능성 콩발효식품 및 콩품종 이용다 양화에 활용 될 수 있을 것으로 기대된다.

\section{감사의 글}

본 연구는 농촌진흥청 국립농업과학원 어젠다사업(과제 번호: PJ010927)의 지원에 의해 이루어진 것임

\section{References}

1. Kim EB, Kim EJ, Lee HN, Lee MK, Oh JS, Kim SO, Lee SY (2008) The quality characteristics of soy cutlets using textured soy protein treated with different enzymes. Korean J Food Culture, 23, 507-513

2. Jeon SH, Lee KA, Byoun KE (2005) Studies on changes of isoflavone and nutrients during germination of soybean varieties. Korean J Human Ecol, 14, 485-489 
3. Messina MJ, Persky V, Setchell KD, Barnes S (1994) Soy intake and cancer risk: a review of the in vitro and in vivo data. Nutr cancer, 21, 113-131

4. Choe JS, Yoo SM, Kim HR, Kim JS, Chang CM (1999) Volatile compounds of Chonggugjang prepared by different fermentation methods and soybean cultivars. J Korean Soc Agric Chem Biotechnol, 42, 111-115

5. Joo EY, Park CS (2010) Antioxidative and fibrinolytic activity of extracts from soybean and Chungkukjang (fermented soybeans) prepared from a black soybean cultivar. Korean J Food Preserv, 17, 874-880

6. Yoo SM, Chang CM (1999) Study on the processing adaptability of soybean cultivars for Korean traditional Chonggugjang preparation. J Korean Soc Agric Chem Biotechnol, 42, 91-98

7. Ko YJ, Son YH, Kim EJ, Lee HH, An SR, Kim DH, Ryu CH (2012) Quality properties of commercial Chungkukjang in Korea. J Agric \& Life Sci, 46, 177-187

8. Kim SH, Yang JL, Song YS (1999) Physiological functions of Chongkukjang. Food Ind Nutr, 4, 40-46

9. Shon MY, Seo KI, Park SK, Cho YS, Sung NJ (2001) Some biological activities and isoflavone content of Chungkugjang prepared with black beans and Bacillus strains. J Korean Soc Food Sci Nutr, 30, 662-667

10. Lee KA (2006) Quality characteristics of castella with Chungkukjang. Korean J Food Cookery Sci, 22, 244-249

11. An SH, Lee SH, Park GS (2008) Quality characteristics of tofu prepared with various concentrations of commercial Chungkukjang powder. Korean J Food Cookery Sci, 24, 258-265

12. Lee HJ, Kim SS, Han CK, Oh HH, Kim HJ, Lee SW, Choi YS, Choi EY, Kim MK, Kim WM (2011) Antioxidative activity and quality characteristics of almond cookies prepared with Job's tears (Coixlachrymajobi L.) Chungukjang. Korean J Food Cookery Sci, 27, 43-54

13. Choi EJ, Lee JS, Chang HB, Lee MS, Jang HD, Kwon YI (2010) Changes in the functionality of Cheonggukjang during fermentation supplemented with Angelica gigas, Rehmanniae Radix, and Red ginseng. Kor J Microbiol Biotechnol, 38, 467-474

14. Park NY, Seong JH, Choi MS, Moon KD, Kwon JH, Jeong YJ (2008) Comparison of functional properties of Cheonggukjang by using red ginseng. J Korean Soc Food Sci Nutr, 37, 261-268

15. Lee YL, Kim SH, Choung NH, Yim MH (1992) A study on the production of viscous substance during the
Cheonggukjang fermentation. J Korean Agric Chem Soc, 35, 202-209

16. Choi SH, Ji YA (1989) Changes in flavor of Chungkookjang during fermentation. Korean J Food Sci Technol, 21, 229-234

17. Choi UK, Ji WD, Chung YG (1998) Characteristics of Chunggugjang produced by Bacillus subtilis DC-2. J Korean Soc Food Sci Nutr, 27, 846-851

18. Lee JJ, Lee DS, Kim HB (1999) Fermentation patterns of Chungkookjang and Kanjang by Bacillus licheniformis B1. Korean J Microbiol, 35, 296-301

19. Lee SY, Kim JY, Baek SY, Yeo SH, Koo BS, Park HY, Choi HS (2011) Isolation and characterization of oligotrophic strains with high enzyme activity from buckwheat Sokseongjang. Korean J Food Sci Technol, 43, 735-741

20. AOAC (1995) Official Methods of Analysis. 16th ed. Association of Official Analytical Chemists, Washington DC, USA, p 1-43

21. Shon MY, Kwon SH, Sung CK, Park SK, Choi SD (2001) Changes in chemical components of Chungkugjang prepared with small black bean. Korean J Life Science, 11, 284-290

22. Lee SY, Park NY, Kim JY, Choi HS (2012) Quality characteristics of rice-doenjang during fermentation by differently shaped meju and adding starter. Korean J Food Nutr, 25, 505-512

23. Kim HE, Han SY, Jung JB, Ko JM, KIim YS (2011) Quality characteristics of Doenjang (Soybean Paste) prepared with germinated regular soybean and black soybean. Korean J Food Sci Technol, 43, 361-368

24. In JP, Lee SK, Ahn BK, Chung IM, Jang CH (2002) Flavor improvement of Chungkookjang by addition of yucca (Yucca shidigera) extract. Korean J Food Sci Technol, 34, 57-64

25. Kim JW, Kim YS, Jeong PH, Kim HE, Shin DH (2006) Physicochemical characteristics of traditional fermented soybean products manufactured in folk villages of Sunchang region. J Fd Hyg Safety, 21, 223-230

26. Kim MH, Lee NH, Choi UK (2008) Fermentation characteristics of Cheonggukjang made of germinated soybean under light condition. J Life Sci, 18, 1420-1425

27. Eom SM, Jung BY, Oh HI (2009) Changes in chemical components of Cheonggukjang prepared with germinated soybeans during fermentation. J Appl Biol Chem, 52, 133-141

28. Kim KJ, Ryu MK, Kim SS (1982) Chungkook-jang koji 
fermentation with rice straw. Korean J Food Sci Technol, 14, 301-308

29. Youn KC, Kim DH, Kim JO, Park BJ, Yook HS, Cho JM, Byun MW (2002) Quality characteristics of the Chungkookjang fermented by the mixed culture of Bacillus natto and B. licheniformis. J Korean Soc Food Sci Nutr, 31, 204-210

30. Park SI (2006) Preparation of Natto (unripe Chungkukjang) using small soybeans and Bacillus subtilis KCCM 11315. Korean J Culinary Res, 12, 225-235

31. Hwang HA, Lee NK, Cho IJ, Hahm YT, Kwon KO, Kim BY (2008) Selection of microorganisms and optimization of manufacture process for cheonggukjang. Korean J Food Sci Technol, 40, 406-411

32. Kim JS, Yoo SM, Choe JS, Park HJ, Hong SP, Chang CM (1998) Physicochemical properties of traditional Chonggugjang produced in different regions. Agric Chem Biotech, 41, 377-383

33. Son DH, Kwon OJ, Ji WD, Choi UK, Kwon OJ, Lee EJ, Cho YJ, Cha WS, Chung YG (2000) The quality changes of Chungugjang prepared by Bacillus sp. CS-17 during fermentation time. J Korean Soc Agric Chem Biotechnol, 43, 1-6
34. Choi UK, Ji WD, Im MH, Choi JD, Chung YG, Son DH (1998) Changes of taste components and palatability during Chunggugjang fermentation by Bacillus subtilis DC-2. J Korean Soc Food Sci Nutr, 27, 840-845

35. Oh GS, Kang KJ, Hong YP, An YS, Lee HM (2003) Distribution of organic acids in traditional and modified fermented foods. J Korean Soc Food Sci Nutr, 32, 1177-1185

36. Park JS, Cho SH, Na HS (2010) Properties of Cheongkukjang prepared with admixed medicinal herb powder. Korean J Food Preserv, 17, 343-350

37. Matsui T, Yoo HJ, Hwang JS, Lee DS, Kim HB (2004) Isolation of angiotensin I-converting enzyme inhibitory peptide from Chungkookjang. Korean J Microbiol, 40, 355-358

38. Ju KE, Oh NS (2009) Effect of the mixed culture of Bacillus subtilis and Lactobacillus plantarum on the quality of Cheonggukjang. Korean J Food Sci Technol, 41, 399-404

39. Beak LM, Kang KM, Park LY, Lee SH (2012) Fermentation and quality characteristics of Cheongkookjang prepared with germinated soybean. Korean J Food Preserv, 19, 547-553 